\title{
Sanal Gerçeklik Yardımıyla Sporu Oyunlaştırmak İçin Tasarlanan Kondisyon Bisikleti Ve Oyun
}

\author{
${ }^{* 1}$ Muhammet Ali LIVV, ${ }^{2}$ Ertuğrul SAATÇI \\ ${ }^{*}$ Bilgisayar Mühendisliği Bölümü, İstanbul Kültür Üniversitesi, İstanbul, Türkiye \\ ${ }^{2}$ Elektirik-Elektronik Mühendisliği Bölümü, İstanbul Kültür Üniversitesi, İstanbul, Türkiye
}

\section{Özet}

$\mathrm{Bu}$ çalışma oyunlaştırarak spor yapmak için tasarlanan bir kondisyon bisikleti ve sanal gerçeklik oyunundan oluşmaktadır. Kullanıcı sanal gerçeklik için geliştirilen oyuna e-postası ve kullanıcı şifresi ile giriş yapar ve isterse zorluk derecesini değiştirir. Zorluk derecesi oyunda yoldaki eğimi artırmaktadır. Oyunda eğim artışı hissini verebilmek için kondisyon bisikletinde zorluk derecesine göre artan sayıda elektro mıknatıs aktif edilir. Aktif edilen elektro mıknatısların ana kasnağa uyguladığı kuvvet sayesinde pedalı çevirmek zorlaşır böylece oyundaki gerçeklik hissi artar. Oyundaki bisikletli karakteri, bisikletten alınan devir sayısına göre hareket ettirilir. Oyun karakteri duraksamaması için takip eden zombi karakteri yakalayana ya da kullanıcı oyundan çıkana kadar devam eder. Oyunda ekranın sol üst köşesinde kullanıcının nabzı, mevcut hızı, geçen süre, hesaplanan yakılan kalori miktarı ve gidilen toplam yol bilgisi gösterilir. Kullanıcı oyundan çıktığı zaman ise yaktığı kalori miktarı veri tabanına kaydedilir. Kullanıcı web ara yüzü sayesinde veri tabanına kaydedilen geçmiş kullanım verilerini takip edebilir.

Anahtar Kelimeler: Sanal Gerçeklik, Kalori Ölçümü, Oyunlaştırma ile Spor, VR Kondisyon Bisikleti

\begin{abstract}
This study consist of an exercise bike designed for sports by gamification and a virtual reality (VR) game. User login the game which is developed for VR by using his/her e-mail and user password and can change the degree of difficulty if he/she wants to. Degree of difficulty increases the slope of the road in the game. Depending on the degree of difficulty, an increasing number of electro-magnets are activated in the exercise bike to give the feeling of increasing slope in the road. Due to the force applied by the activated electro-magnets to the main pulley, turning the pedal becomes difficult thus, the sense of reality in the game increases. In the game, the character with the bike is moved according to the number of revolutions received from the bike. The game continues until the character is caught by the following zombie character so that the user does not stop or until the user exits the game. Pulse, current speed, elapsed time, calculated burned calories and total route information are shown in the game, in the upper left corner of the screen. When the user exits the game, the amount of calories he/she burn is recorded in the database. The user can track historical usage data saved in the database via the web interface.
\end{abstract}

Key Words: Virtual Reality, Calorie Measuremen t, Sports by Gamification, Exercise Bike

\section{Giriş}

Çağımızın en büyük sorunlarından biri olan obezite giderek daha büyük bir sorun haline gelmeye başlamıştır. Obezitenin temel nedenlerinden biri de hareketsiz yaşamdır. Özelikle Covid-19 pandemi döneminde çeşitli yaş grupları için alınan kısıtlama kararları ve korunma amaçlı insanların evlere kapanmasıyla daha az hareketli bir yaşam sürülmeye başlanmış bu da obez birey sayısındaki

*Corresponding author: Address: Faculty of Engineering, Department of Computer Engineering İstanbul Kültür University, 34158, İstanbul TURKEY. E-mail address: 1700004728@stu.iku.edu.tr, Phone: +905071444516 
artışta bir hızlanmaya neden olmuştur [1]. Bu çalışmayla günümüzde popülaritesi giderek artan sanal gerçeklik teknolojisi vasıtasıyla sporu oyunlaştırıp insanları hareket etmeye motive etmek amaçlanmaktadır.

Sanal gerçeklik gözlüğü ve kondisyon bisikleti ile sporu oyunlaştırarak yaptırmayı amaçlayan çeşitli akademik çalışmalar ve ticari ürünler vardır. Bu çalışma çeşitli yönleriyle diğer çalışmalardan ayrışmaktadır. Örneğin 2016 yılında Indiegogo üzerinden büyük bir ön sipariş alma başrısı sağlayan Virzoom PlayStationVR, HTC Vive ve Oculus Rift gibi yüksek maliyetli sanal gerçeklik gözlüklerine ihtiyaç duyarken bu projede Google Cardboard veya benzeri düşük maliyetli bir sanal gerçeklik gözlüğü kullanılabilmektedir [2]. Bu da maliyet açısından bu çalışmayı avantajlı bir konuma getirmektedir. Geliştirilen kondisyon bisikleti ve oyun ile belli bir platforma bağlı kalmadan kondisyon bisikleti ile oyun arasındaki etkileşim arttırılmış olduğundan, bu çalışma belli bir oyuna entegre edilen MineBike çalışması gibi çalışmalardan farklılık göstermektedir [3]. Aynı zamanda geliştirilen web ara yüzü sayesinde kullanıcı geçmiş kullanımlarını takip edip diğer kullanıcılara göre siralamasını görebilmekte bu da kullanıcının motivasyonunu arttırmasına yardımcı olmaktadır. Ek olarak çalışma web ara yüzü sayesinde, [4]'de olduğu gibi anlık oyun deneyimi dışında sağladığı web platformu sayesinde farklılık göstermektedir. Ayrıca zorluk seviyesini ayarlamak için geliştirilen manyetik zorluk sistemi ile mekanik sürtünme kaynaklı yıpranmaları önleyerek daha uzun bir kullanım ömrü sağlamakta ve zorluk değişimine kondisyon bisikletinin daha hızı bir cevap vermesiyle kendine özgü bir yapı sunmaktadır.

\section{Materyal ve Metod}

Kullanıcı kondisyon bisikletine binip geliştirilen VR uygulamasını başlatır ve ardından daha önce web ara yüzü yardımıyla veri tabanına kayıt olduğu tanımlı kullanıcı adı ve şifresi ile uygulamaya giriş yapar. Oyun başlamadan önce ayarlardan oyun zorluk seviyesi değiştirilebilir. Zorluk seviyesine göre artan sayıda elektro mıknatısa röle üzerinden akım verilip aktif hale getirilirler. Oyun başladığında yola aktif edilen elektro mıknatıs sayısına göre eğim verilir. Kullanıcı oyuna başladığında enkoderdan okunan devir sayısı bluetooth bağlantı üzerinden telefona gönderilip gerekli hesaplamalar yapılarak VR oyunu içinde hız, yakılan kalori gibi veriler gösterilir. Ayrıca kullanıcı sistemdeki nabız ölçeri kullanmak isterse, kullanıcı nabzı ekranda gösterilip spor için uygun nabız aralığında olup olmadığı kontrol edilerek değil ise nabız uyarısı gösterilir. Oyunda kullanıcıyı sürekli hareket halinde tutmayı sağlamak amacıyla bir zombi kovalar. Kullanıcı oyundan çıktığında ya da zombi yakaladığında oyun biter ve kullanıcı istatislikleri geliştirilen API yardımıyla veri tabanına kaydedilir. Kullanıcı istediği zaman web ara yüzüne girerek geçmiş istatisliklerini görüntüleyebilir.

\subsection{Hesaplamalar}

Kullanıcının pedalı çevirmesi için uyguladığı kuvvet yardımıyla harcadığı enerji hesaplanıp harcanan kalori bulunur. Ayrıca kullanıcının yaş verisi kullanılarak hedef nabız aralığı bulunur eğer sensörler yardımıyla ölçülen nabız hedef nabız aralığında değilse kullanıcıya uyarı verilir.

\subsubsection{Kondisyon Bisikletinde Harcanan Kalori Hesabının Yapılması}

Kondisyon bisikleti ile spor yapan bir kişinin harcadığı enerji miktarını hesaplamak için termodinamiğin 1. kanunundan faydalanılır. Termodinamiğin 1. kanununa göre enerjinin 
korunumu esastır. Böylece enerji yoktan var olmadığı gibi vardan yok olmaz sadece farklı sistemler arasında dönüşüme uğrar [5]. Bu esasa göre kondisyon bisikletini kullanan sporcunun pedalları çevirmesi ile bisiklete aktardığı enerji, harcadığı enerji miktarına eşit olacaktır. Kondisyon bisikletine aktarılan güç değerini hesaplamak için Eşitlik 1'de verilen denklem kullanılır. Bu denklem dönen cisimlerde güç hesabı yapabilmek için elde edilmiştir [6].

$$
P=\frac{\tau \times \omega}{\eta}
$$

$\mathrm{Bu}$ denklemde $\mathrm{P}$ (Watt) güç, $\tau(\mathrm{Nm})$ tork, $\omega(\mathrm{rad} / \mathrm{s})$ açısal hız ve $\eta$ verimi ifade etmektedir. Ortalama bir insanın pedal çevirme işlemindeki verimi $(\eta) \% 20-30$ arasında verilmektedir [7]. Belirtilen verim değeri sporcunun harcadığı toplam enerjinin kondisyon bisikletinin pedalını çeviren mekanik enerjiye oranıdır. Geri kalan enerji ise ortama 1sı olarak atılır. Bu çalışma kapsamında verim değeri \%25 olarak alınmaktadır. Sistemdeki diğer mekanik kayıplar oldukça küçük olduğundan ihmal edilmektedir.

$\tau$ (tork) değerini hesaplayabilmek için bisiklet çarkına uygulanan kuvvet $\mathrm{F}$, pedal kol uzunluğu $\mathrm{L}$ ile çarpılmalıdır. Belirtilen kuvvet ve pedal kol uzunluğu Şekil 1'de şematik olarak gösterilmiştir. $\mathrm{Bu}$ çalışmada $\mathrm{L}=0.15 \mathrm{~m}$ ve pedal çarkını döndürmek için gerekli kuvvet ise zorluk derecesi artırılmadığında yani hiçbir elektro mıknatıs aktif edilmediğinde sabit neodyum mıknatıslar etkisiyle 38 N'dur. Bu değerler kondisyon bisikleti üzerinde yapılan ölçümler ile elde edilmiştir. Böylece $\tau$ (tork) değeri $5.7 \mathrm{Nm}$ olur. Zorluk derecesi artırıldığında aktif edilen her bir elektro mıknatıs için bu değer $1.6 \mathrm{Nm}$ daha artar.

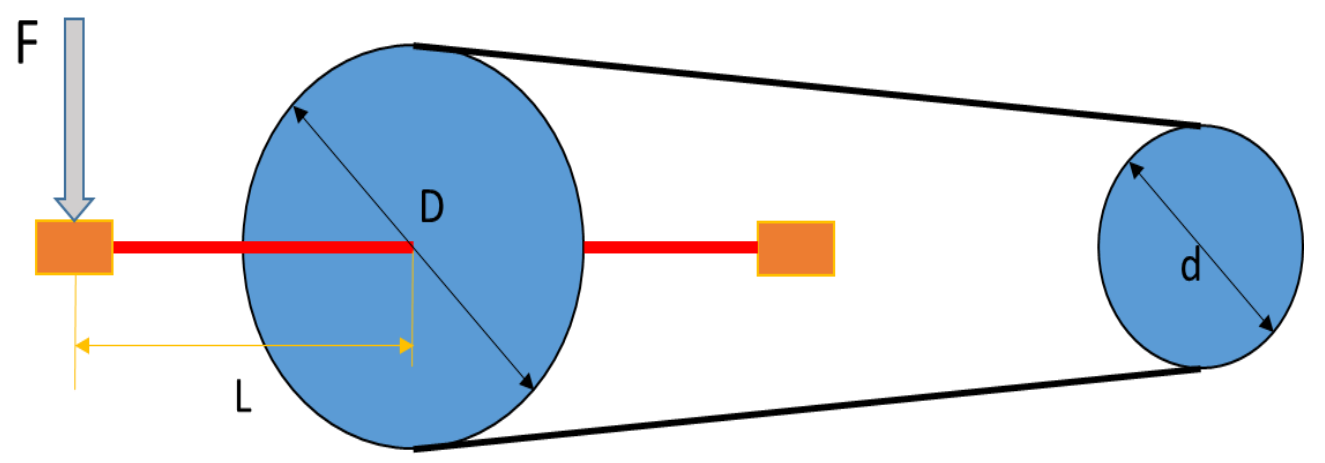

Şekil 1. Şematik bisiklet çarkları ve pedal gösterimi

$\mathrm{Bu}$ çalışma kapsamında dönü sayısı, d çapındaki kasnağın bağlı olduğu enkoderdan okunmaktadır. Enkoder saniyedeki dönü sayısını yani dönünün frekansını (f) verir. Bu ölçümden yola çıkarak pedal çarkının açısal hızını Eşitlik 2 ile hesaplayabiliriz. 


$$
\omega_{\text {Pedal }}=\frac{d}{D} 2 \pi f
$$

Bu denklemde pedalın üzerinde olan kasnağın çapı (D) 200 mm; enkoderin bağlı olduğu kasnağın çapı (d) ise $25 \mathrm{~mm}$ 'dir.

Böylece Eşitlik 1 kullanılarak güç yani birim zamanda harcanan enerji miktarı hesaplanabilir. P güç değerinin sporcunun pedal çevirme süresi t ile çarpılması ise Eşitlik 3'te görülen yaktığı enerji miktarı E'yi Joule cinsinden verecektir.

$$
E=P x t
$$

Joule biriminde hesaplanan enerji değerinin Eşitlik 4 yardımıyla kaloriye çevrilmesi ile sporcunun harcadığı kalori miktarı elde edilmiş olur.

$$
\text { kalori }=E \times 0.239
$$

\subsubsection{Optimal Nabız Aralığının Belirlenmesi}

Orta tempolu egzersizler esnasında ideal nabız aralığ hesabında minimum ideal nabız atış sayısını bulmak için Eşitlik 5 ve maksimum ideal nabız atış sayısını bulmak için ise Eşitlik 6'daki bağıntıdan yararlanılmıştır [8]. Yaş aralıklarına uygun tespit edilen nabız aralıkları, orta tempolu egzersizlerde gerçekleşen kalori yakımının saptanmasında standart kabul edilmiştir.

$$
\begin{gathered}
\text { Minimum ideal nabız }=220-\text { Yaş } x 0.5 \\
\text { Maksimum ideal nabız }=220-\text { Yaş } x 0.7
\end{gathered}
$$

\subsection{Kondisyon Bisikletinin Mekanik Geliş̧tirmeleri}

Cihaz prototipini daha hızlı ve uygun maliyetli geliştirmek için voit bs 101 marka kondisyon bisikletinin tüm elektronik aksamı sökülüp yeni geliştirilen elektronik aksam monte edilmiştir. Yaklaşık $5 \mathrm{~kg}$ ağırlığındaki ana kasnak çıkartılıp yerine enkoder takılarak cihazın ağırlığı azaltılmıştır. Ayrıca kasnağa zorluk ayarında kullanılmak üzere yerleştirilmiş metal bir ipin çektiği sabit mıknatıslar yerine, elektro mıknatıslar yerleştirilmiş ve zorluk seviyesi değiştirme işlemi daha hızlı ve mekanik yerine elektronik bir sistemle kontrol edilebilir hale getirilmiştir. Yapılan bu değişiklikler ile mekanik sürtünmeden kaynaklı parça aşınmaları ortadan kaldırılarak cihaz ömrü 
uzatılmıştır. Cihazın eklentiler yapılmış hali Şekil 2'de görülmektedir.

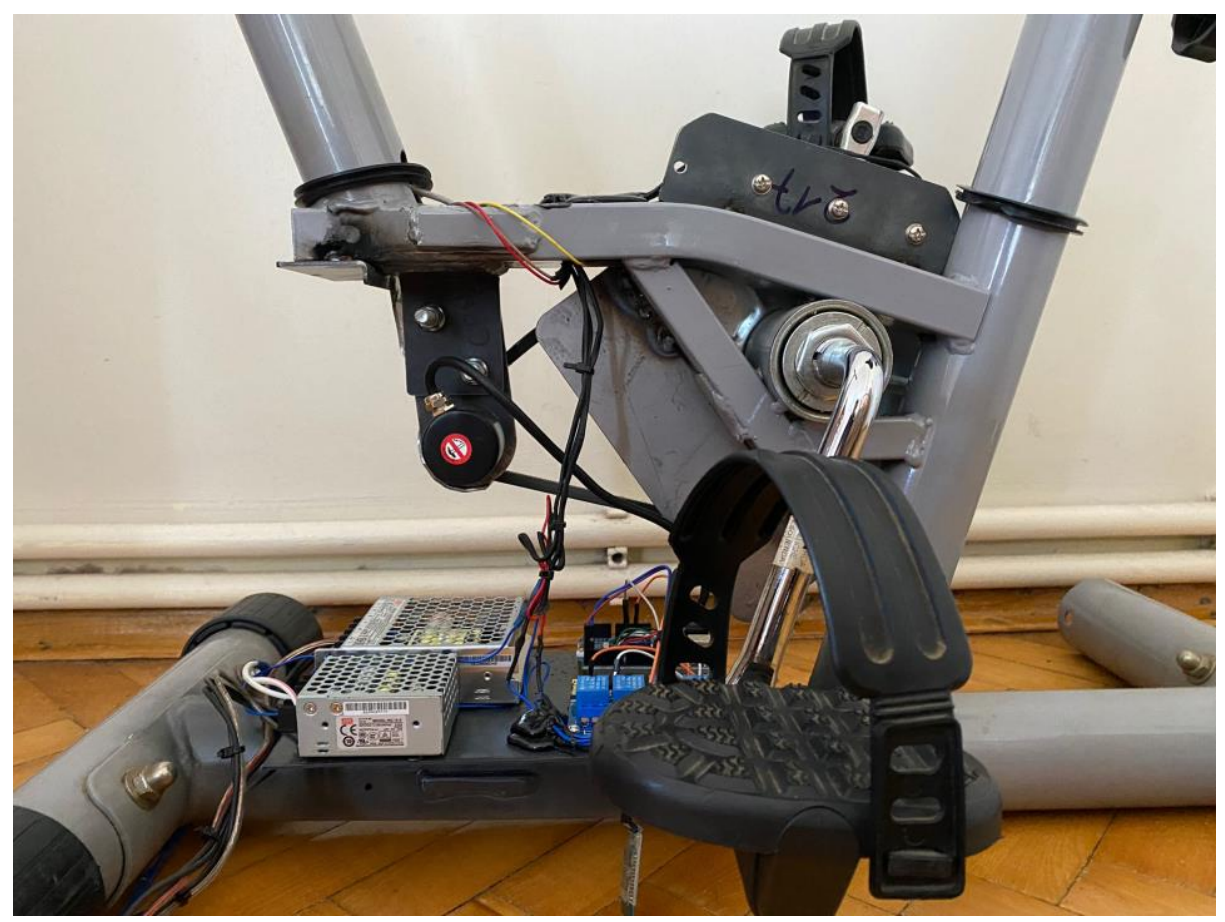

Şekil 2. Eklentiler yapılan voit bs 101 marka kondisyon biskleti

\subsection{Kondisyon Bisikletinin Elektronik Geliştirmeleri}

Voit bs 101 marka bisikletin tüm elektronik aksamı sökülerek Şekil 3'te bağlantı şeması görülen devre tasarlanmıştır. Bu devrede $12 \mathrm{~V}$ ile çalışan elektro mıknatısları beslemek için $12 \mathrm{~V}$ güç kaynağ 1 ve devre üzerinde bulunan Arduino Uno'yu beslemek için ise $5 \mathrm{~V}$ güç kaynağ kullanılmıştır. Elektro mıknatısları açıp kapatma işlemi röle yardımıyla yapılmaktadır. Nabız ölçümü için iki adet nabız sensörü, haberleşme için HC-06 bluetooth modülü ve pedal çevirme sayısının ölçümü için ise enkoder kullanılmıştır. Enkoderdan ölçülen devir sayısı ve nabız sensöründen ölçülen nabız değeri bluetooth modülü yardımıyla uygulamaya gönderilmektedir. Oyun üzerinde ayarlanan zorluk derecesi bilgisi yine bluetooth bağlantı ile alınarak röle yardımıyla yeterli sayıda elektro mıknatıs aktif edilmektedir. 


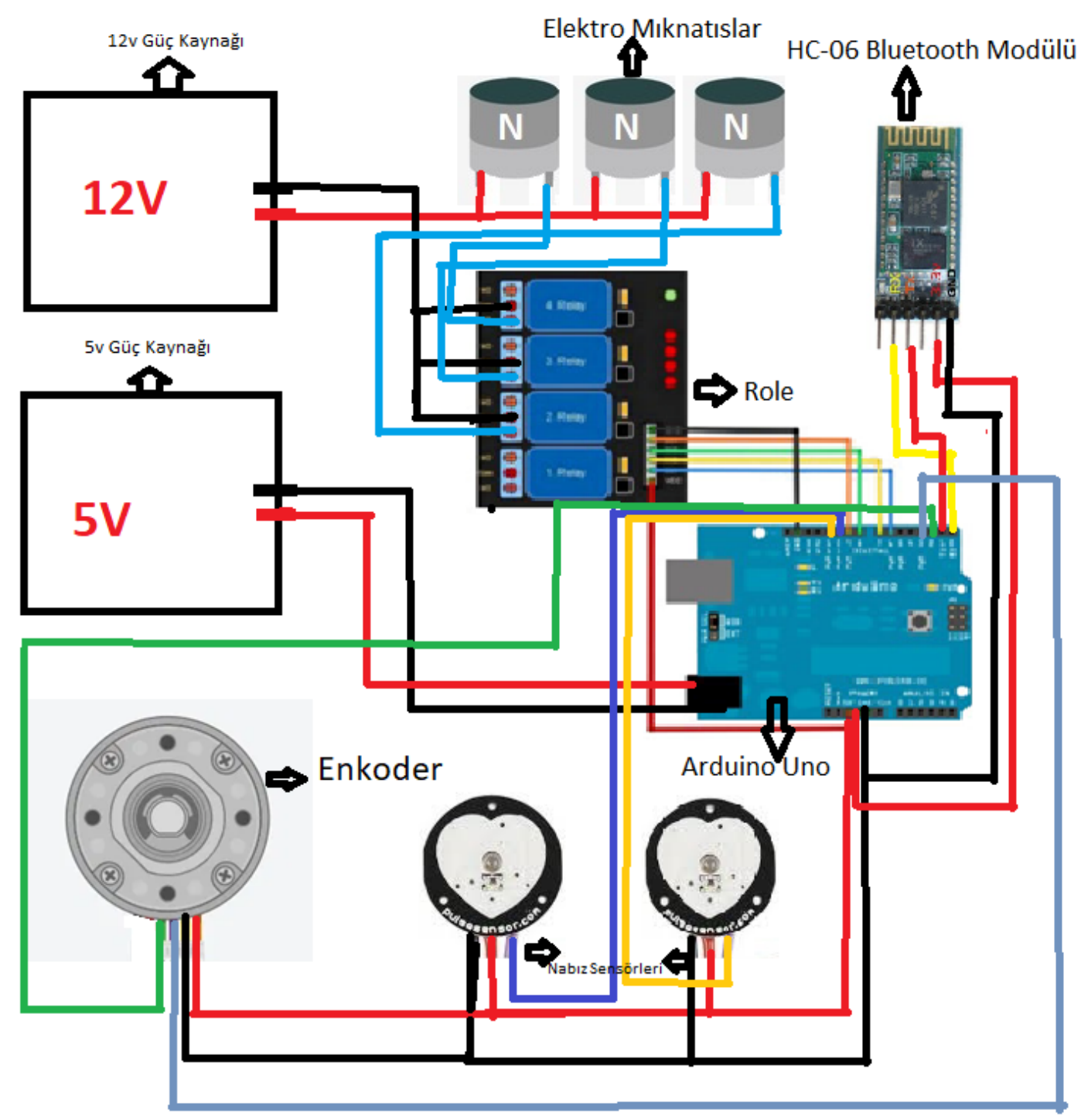

Şekil 3. Kondisyon bisikleti için tasarlanan elektronik devrenin bağlantı şeması

\subsection{VR Oyunu ve Web Arayüzü}

VR uygulaması Unity oyun motoru ve Google Card Board SDK'sı kullanılarak geliştirilmiştir. Oyunda iki zemin kullanılmıştır ve karakter bir zeminden diğerine geçtiğinde arkada kalan zemin karakterin bulunduğu zeminin önüne getirilmiş ve bu döngü devam ettirilerek oyunda süreklilik sağlanmıştır. Döngü karakterin durmasını önlemek için onu takip eden zombi karakteri yakalayana ya da kullanıcı oyundan çıkana kadar devam etmektedir. Zorluk seviyesi kullanıcı tarafından ayarlar sekmesi yardımıyla değiştirilebilmektedir.

VR oyununa giriş kullanıcı e-posta adresi ve şifresi ile Şekil 4.a'da görülen giriş ekranından yapılmaktadır. Şekil 4.b'de görülen VR gözlüğü gibi herhangi bir düşük maliyetli VR gözlüğü oyunda kullanılabilmektedir. Kullanıcı oyunda yaktığı kaloriyi, geçirdiği süreyi ve nabız atış sayısını Şekil 4.c'de görüldüğü gibi oyun ekranından takip edebilmektedir. 


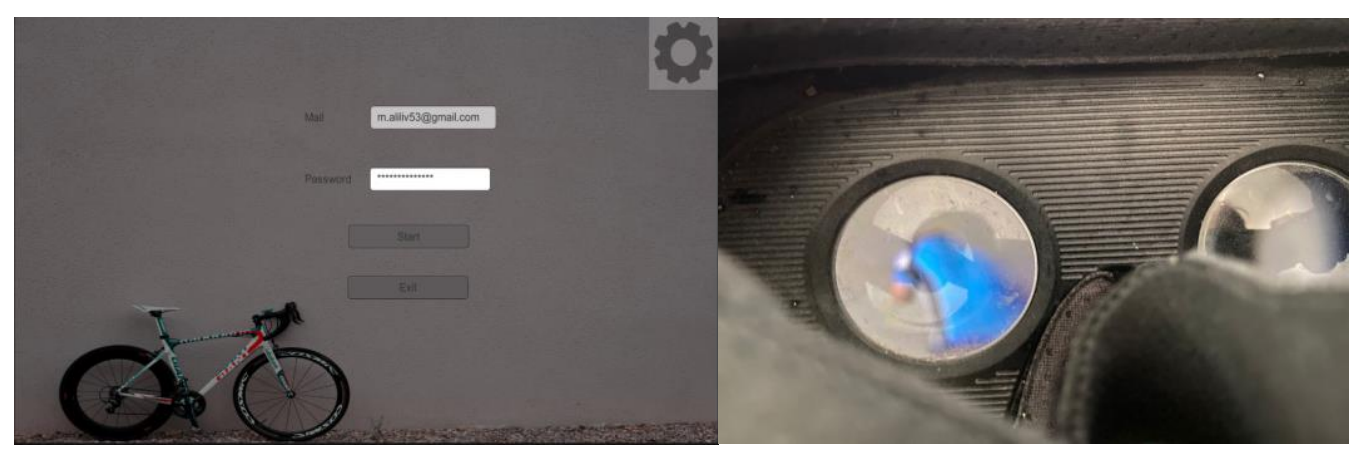

(a)

(b)

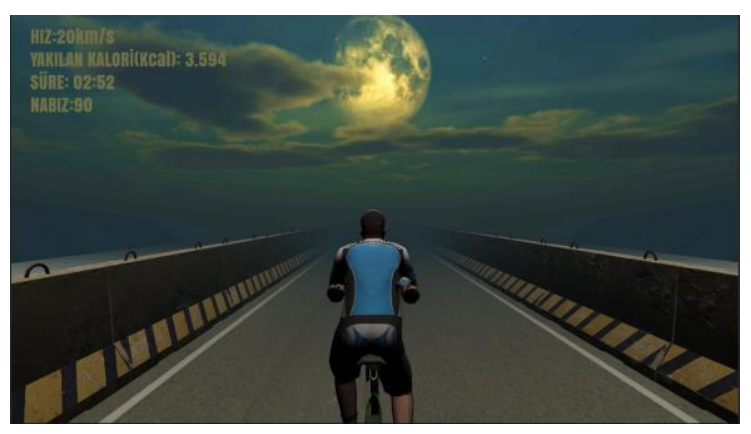

(c)

Şekil 4. (a) Oyun giriş ekranı, (b) VR gözlük üzerinde oyun ve (c) Oyun ekranı

Kullanıcı geçmiş verilerin takibini önyüzü Reactjs ile hazırlanmış web arayüzünden yapabilmektedir. BackEnd kısmı ise .Net Core ile yazılmış bir API'den oluşmaktadır. Kullanıcı Şekil 5.a'da görülen ekran üzerinden e-posta ve şifresi ile giriş yaparak geçmiş kullanım istatisliklerini Şekil 5.b'de gösterildiği gibi bir sayfa üzerinden takip edebilmektedir.

\section{LIVFITS}

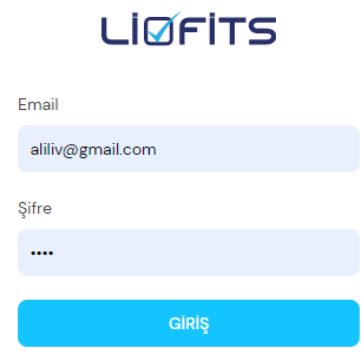

\begin{tabular}{llll}
\multicolumn{3}{l}{ Kullanım İsnatislikleri } \\
\# & Tarih & Yakılan Kalori & Süre(dk) \\
1 & 01.08 .2021 & 83 & 16.30 \\
2 & 02.08 .2021 & 41 & 9.07 \\
3 & 04.08 .2021 & 107 & 21.40
\end{tabular}

(a)

(b)

Şekil 5. (a) Kullanıcı web giriş ekranı ve (b) kullanıcı kullanım verileri 


\section{Tartışma ve Sonuç}

Covid-19 pandemi döneminde kapalı spor salonlarına rağbet azalmıştır ve pandemi sonrasında da insanların bir kısmının toplu spor salonlarında spor yapmak yerine bireysel olarak spor yapma alışkanlığını devam ettireceği öngörülmektedir. $\mathrm{Bu}$ durum ise insanların evlerinde spor yapabilmeleri için spor ekipmanları almalarına neden olacaktır. Geliştirilen ürünün ticarileştirilmesi durumunda halihazırda var olan kondisyon bisikletleri karşısında VR teknolojisi yardımıyla sporu oyunlaştırarak yapmayı sağlaması nedeniyle avantaja sahip olacağı düşünülmektedir.

Çalışmanın devamında bisikletin tek bir oyuna bağlı kalmaması için bisiklet ile kullanılabilecek daha fazla VR uygulaması geliştirilebilir. Ek olarak ilerleyen dönemlerde kullanıcıların kullanım istatisliklerini takip ettiği web arayüzünde, kullanıcılara geçmiş verilerine göre spor programları öneren bir geliştirme yapılabilir. Söz konusu geliştirmelerin yapılması durumunda geliştirilen ürüne ilgi daha da artabilecektir.

\section{Referanslar}

[1] E. Tar, ve D. Atik, "Pandemi Döneminde Çocuklarda Obezite Riski Diyabet", Obezite ve Hipertansiyonda Hemşirelik Forumu Dergisi, cilt 12, sayı 2, s. 40, 2020.

[2] Indiegogo, URL:https://www.indiegogo.com/projects/virzoom-virtual-reality-bike-controller-and-games\#/,(10

Temmuz, 2021.)

[3] Y. Huh, GT Duarte ve M. El Zarki, "MineBike: Exergaming with Minecraft," 2018 IEEE 20th International Conference on e-Health Networking, Applications and Services (Healthcom), s. 1-6, 2018.

[4] Y. Wang, K. Ijaz ve R. A. Calvo, "A software application framework for developing immersive virtual reality experiences in health domain," 2017 IEEE Life Sciences Conference (LSC), s. 37-30, 2017.

[5] Y. Çengel, ve M.A. Boles, Mühendislik Yaklaşımıyla Termodinamik, Literatür Yayıncılık/ McGraw-Hill, 1996.

[6] R. C. Hibbeler, Mühendislik Mekaniği: Dinamik, Literatür Yayıncılık, 2016.

[7] D. G. Wilson, ve T. Schmidt, Bicycle Science, MIT Press, 2004.

[8] Türk Kalp Vakfı, URL: https://tkv.org.tr/saglikli-bilgiler/makaleler/egzersiz-ve-kalp, (1 Ağustos, 2021.) 